\title{
Molecular Signature
}

National Cancer Institute

\section{Source}

National Cancer Institute. Molecular Signature. NCI Thesaurus. Code C48181.

The set of characteristics, including the expression of certain genes, proteins,

polysaccharides and/or lipids, that can identify what cells or tissues are present in a

biological sample and/or indicate whether abnormal cells or tissues are present. 